\title{
El modelo figural para una historia de la historiografía de la ciencia
}

\author{
The Figural Model for a History of Science Historiography
}

\author{
María Martini \\ mariadelosangelesmartini@gmail.com \\ Profesora asociada \\ Universidad de Buenos Aires \\ Calle Pasteur, 784, 20- C - CABA \\ 1028 - Buenos Aires \\ Argentina
}

\section{Resumen}

El análisis de los vínculos entre diferentes textos de historia de la ciencia supone construir o asumir un concepto de historia de la historiografía de la ciencia. Hayden White ha señalado que el modelo figural propuesto por Erich Auerbach para la historia literaria constituye un paradigma de conexiones entre sucesivos intentos de representación. Ese esquema despliega una estructura de trama en la que se crean vínculos por medio de actos performativos de señalamiento desde el presente hacia el pasado, constituyendo a un mismo tiempo los acontecimientos anteriores como figuras y los presentes, como su consumación. El propósito de este artículo es construir una historia fragmentaria de la historiografía de la ciencia a partir del modelo figural. En ese sentido, interpreto un conjunto de escritos historiográficos de Steven Shapin como consumación de una serie de mediaciones figura-cumplimiento que se conformaron en torno al origen de la ciencia moderna en la Inglaterra del siglo XVII.

\section{Palabras clave}

Historia de la historiografía; Historia de la ciencia; Tradición.

\begin{abstract}
The analysis of the linkages between different texts on history of science entails formulating, or employing, a concept of history of science historiography. Hayden White holds that the figural model for literary history, proposed by Erich Auerbach, constitutes a paradigm of relationships between successive attempts of representation. This scheme displays a plot structure in which linkages are created through performative acts that point from the present to the past, and, at the same time, establish the earlier events as figures and the present events as their fulfillment. The purpose of this article is to elaborate a fragmentary history of science historiography by making use of the figural model. In this sense, I examine a set of historiographic writings by Steven Shapin as the fulfillment of a series of figure-fulfillment mediations shaped around the origin of modern science in seventeenth-century England.
\end{abstract}

\section{Keywords}

History of historiography; History of science; Tradition.

Recibido el: 15/2/2013

Aprobado el: 15/7/2013 
Los trabajos historiográficos de Steven Shapin exhiben un reordenamiento y una reelaboración de los límites diseñados por los enfoques disciplinares en el marco del debate historiográfico internismo/externismo así como también en las distintas perspectivas de la sociología del conocimiento científico. Shapin crea movimientos de rupturas en busca de los recursos metodológicos que le permitan disolver los compromisos cristalizados en los diferentes espacios disciplinares. Toma aspectos parciales de las tesis de otros autores y los "desengancha" para emplearlos de una manera inesperada en la resolución de problemas, los resignifica en un proceso que pone en marcha la aprehensión distintivamente histórica de los eventos. De ahí que considerar la obra de Shapin tomando como presupuesto que constituye la base de puesta a prueba de los principios teóricos del Programa Fuerte de la sociología del conocimiento científico obstaculiza, no solo la comprensión de su obra, sino que obliga a comprometerse con un concepto de historia de la ciencia que parece reducirla a un mero auxiliar de las otras disciplinas metacientíficas: la filosofía y la sociología de la ciencia.

En el presente trabajo abordo la obra de Shapin dedicada a la ciencia en la Inglaterra del siglo XVII para examinarla en relación con un conjunto de trabajos históricos consagrados a tender los vínculos entre los orígenes de la ciencia moderna inglesa y la religión. El problema del que parto es el de cómo conceptualizar la relación que un texto histórico específico establece con otros proclamando la pertenencia a un estilo o perspectiva historiográfica, bajo qué criterio enlazar esas producciones historiográficas sucesivas y diferentes. Si bien la tarea que me propongo es construir un fragmento de la historia de la historiografía de la ciencia y no una historia completa, ella envuelve, no obstante, la producción o apropiación de un concepto de historia de la historiografía de la ciencia. El esquema que me propongo aplicar es el modelo figural, que Hayden White (2010) retoma de la propuesta realizada por Erich Auerbach en su intento de producir un concepto de historia literaria. De acuerdo con la interpretación de White, Auerbach construye un modelo explicativo para dar cuenta de la constitución de una tradición literaria como una relación genealógica de sucesivas expropiaciones. Me propongo resaltar el valor cognitivo del señalamiento de las relaciones genealógicas diseñadas desde la misma obra shapiniana para la comprensión de la novedad y la continuidad que exhibe.

\section{La causalidad figural y la formación del canon historiográfico}

Una parte importante de los historiadores y sociólogos de la ciencia a los que se aproxima Shapin examinaron las relaciones entre ciencia y religión en la Inglaterra del siglo XVII. Sus obras constituyen un conjunto de trabajos que van moldeando distintas formas de configurar un estilo contextualista.

Si asumimos la tesis whiteana de la naturaleza figurativa de los modos diferentes de construir los campos históricos y de las maneras diversas en que pueden ser conceptualizadas las relaciones entre los fenómenos de tales campos y sus contextos, podemos admitir que esas nuevas construcciones contextualistas conquistaron sus efectos explicativos específicos, al igual que las explicaciones contextualistas del siglo XIX, por medio del modo figurativo de la ironía. La 
estrategia contextualista presentó descripciones de los campos históricos de tal modo que un evento, agente o institución es representado como opuesto a su entorno inmediato. El trabajo contextualista opera sobre la entidad en cuestión inicialmente descrita como aparentemente extraña y, en consecuencia, incomprensible como típica de su entorno. El análisis asume una redescripción simultánea del entorno y de la entidad que se explicará. Lo que es originalmente descrito en un metalenguaje es progresivamente redescrito en otro para crear un cambio de cualidades y texturas entre la entidad que se explica y el entorno. El entorno se transforma en un contexto identificable y lo mismo ocurre con la entidad, que es diferenciada de otras entidades similares, convirtiéndosela en una expresión del contexto compartido por todas ellas (WHITE 1999, p. 53).

Las versiones históricas que abordo comparten muchos de los rasgos de esa caracterización de la estrategia contextualista; sin embargo, no parece suficiente tomar en consideración el modo de tramar y el modo de argumentación de esas obras para interpretar cómo se constituye por medio del relato shapiniano el armado de su ascendencia. Diversas obras historiográficas podrían analizarse formalmente de acuerdo con las categorías analíticas de White y ser declaradas como contextualistas, pero no constituirían por ello un precedente o referente para Shapin.

Considero que el concepto de causalidad figural ${ }^{1}$ propuesto por Hayden White constituye una herramienta de análisis fructífera para clarificar el proceso de constitución de una perspectiva, tradición o, de modo más general, de líneas interpretativas historiográficas. Sostengo además que la interpretación whiteana de la causalidad figural es compatible con la concepción de los actos de habla de John Austin, de modo que es posible comprender el establecimiento de un vínculo figural entre distintos textos historiográficos como un acto performativo realizado en el relato mismo de quien se asume como "descendiente" o de quien pretende historiar posiciones historiográficas diversas.

Como es bien sabido, John Austin llama "performativas" a ciertas expresiones para indicar "que emitir la expresión es realizar una acción y que esta no se concibe normalmente como el mero decir algo" (AUSTIN 2008, p. 47). Eso equivale a decir que hay casos en los que decir algo es hacer algo. $Y$, más, el autor deja traslucir su inquietud acerca del carácter performativo de toda expresión (AUSTIN 2008, p. 147, n. 2). Según el análisis austiniano, el uso del lenguaje puede comprenderse en tres sentidos o dimensiones diferentes: el acto locucionario, que equivale a "expresar cierta oración con cierto sentido y referencia, lo que a su vez es aproximadamente equivalente al 'significado' en el sentido tradicional" (AUSTIN 2008, p. 153). Los actos ilocucionarios, que poseen una cierta fuerza convencional y son actos que hacemos al decir algo. $\mathrm{Y}$,

\footnotetext{
${ }^{1}$ White interpreta el concepto de causalidad figural a partir del modelo figura-cumplimiento que Auerbach emplea en Mímesis para concebir una historia de la literatura occidental. White considera que ese modelo puede hacerse extensible a la constitución de cualquier historia, ya que constituye una noción de lo que es historiar sucesivas formas de representar. En ese sentido considero que el modelo figura-cumplimiento puede ser fértil para el análisis y constitución de una historia de la historiografía de la ciencia. Excede al objetivo de este trabajo realizar un análisis crítico de la obra de Auerbach y de las apropiaciones transformadoras que realiza White de dicha obra. Tomamos el modelo figura-cumplimiento desde la interpretación whiteana.
} 
por último, los actos perlocucionarios, "los que producimos o logramos porque decimos algo" (AUSTIN 2008, p. 153). De esos usos del lenguaje, considero que la constitución de una tradición o una perspectiva por medio del señalamiento retrospectivo de textos sucesivos debe verse como un acto ilocucionario.

Así, para establecer la pertenencia de un conjunto de textos a una tradición, estilo o perspectiva no es suficiente determinar una vinculación mediante la identificación de similitudes como efectos determinados por causas previas. La diversidad de semejanzas que puede instituirse parece no tener límites de tal manera que habilita la proliferación de un sinnúmero de historias alternativas. En cambio, podemos tomar como criterio de la constitución del vínculo de una tradición o perspectiva el acto ilocucionario que instaura retrospectivamente una relación de descendencia entre un texto posterior y uno anterior. Interpretamos las expresiones de las "decisiones tomadas por una cantidad de agentes históricos" como los actos ilocucionarios "de considerarse a sí mismos y a su dotación cultural como si hubieran descendido realmente a partir del prototipo anterior" (WHITE 2010, p. 36).

La realización de esos actos de descendencia opera en la institución de relaciones figura-cumplimiento. La noción de cumplimiento, señala White, no debe considerarse como parte de una relación causal determinista ni como la realización gobernada teleológicamente por un potencial inherente: "[p]ropongo denominar a este modo distintivamente histórico de causación con el término de causalidad figural" (WHITE 2010, p. 35). Ahora bien, White destaca que nos hallamos aquí en 140 presencia de una concepción estética de la relación figura-cumplimiento:

[D]ecir [...] que un acontecimiento histórico es el cumplimiento o consumación de otro anterior [...] supone decir que los acontecimientos históricos pueden relacionarse con otros de la misma manera en que una figura se relaciona con su consumación en una narrativa o poema [...] en la forma en que la premisa de una broma se consuma en su remate o en que los conflictos en una escena introductoria de una pieza se cumplen en su desenlace. La figura posterior consuma a la anterior repitiendo los elementos presentes, pero con una diferencia (WHITE 2010, p. 35-38).

Esa interpretación figural se proyecta como modelo para conceptualizar tanto las relaciones entre acontecimientos específicamente históricos en la trama de las representaciones históricas como la relación entre sucesivas representaciones historiográficas. En cualquiera de esos casos, los elementos vinculados deben ser presentados con una articulación doble: los términos anteriores deben ser expuestos como consumaciones de las figuras que los precedieron y los términos posteriores como prefiguraciones de elementos posteriores.

Dado que nuestro interés se centra en la relación entre sucesivas representaciones historiográficas, podemos preguntar: ¿Qué está haciendo un historiador al expresar la relevancia para con su obra de un texto o un conjunto de textos que lo preceden? Realiza el acto ilocucionario de constituir un canon como promesa a seguir $y$, con él, inaugura una línea interpretativa historiográfica. El sentido de las conexiones sucesivas en una línea historiográfica se emplaza en el acto retrospectivo de apropiación de un texto previo por medio 
del procedimiento de considerarlo una figura relativa a un texto posterior. El acto de expropiación señala más lo nuevo y original del presente que su mera continuidad con el pasado señalado. A la vez, un texto histórico prefigurado "permanece abierto a apropiaciones retrospectivas por parte de cualquier grupo que en adelante opte por el mismo como prototipo legitimador de su propio proyecto de auto-creación y por lo tanto como elemento de su genealogía" (WHITE 2010, p. 46).

Podemos aproximar el modelo figura-cumplimiento al género Geistesgeschichte, que Richard Rorty postula como el género, por excelencia, formador del canon de la historiografía de la filosofía. La Geistesgeschichte es una reinterpretación que funda un elenco de personajes históricos por medio de "un relato dramático" que señala la manera en que llegamos a plantearnos problemas que hoy resultan ineludibles. El resultado es una historia con moraleja y "la moraleja por extraer es la de que hemos mantenido - o no hemos mantenido - el rumbo correcto al plantear las cuestiones filosóficas que últimamente hemos planteado, y que el Geisteshistoriker está justificado al adoptar determinada problemática" (RORTY 1990, p. 81). Así, el Geisteshistoriker conforma un relato de autojustificación, que, a la vez, está impulsado por la búsqueda de una mayor conciencia, porque, como lo expresa Rorty:

[...] se propone mantenernos conscientes del hecho de que aún estamos en camino, de que el dramático relato que nos ofrece ha de ser continuado por nuestros descendientes. Cuando es plenamente consciente, se pregunta si acaso todas las cuestiones discutidas hasta ahora no han sido parte de "convenciones contingentes" de épocas pasadas. Insiste en el hecho de que aun cuando algunas de ellas hayan sido necesarias e ineludibles, no sabemos con certeza cuáles fueron (RORTY 1990, p. 83).

El modelo figura-cumplimiento le otorga a esta "conversación autojustificatoria" con textos del pasado el sentido de una promesa siempre renovada e incumplida en la medida en que el establecimiento de todo nuevo canon innovador es un acto en el que se produce la expropiación de textos del pasado por un texto presente sin que este último llegue nunca a ser "completo" en el cumplimiento de la promesa en que fueron constituidas las representaciones previas. Siempre "permanecerá abierto" a futuras expropiaciones que construirán nuevos cánones que desafiarán los ya cristalizados.

\section{Vínculos y expropiaciones}

Las marcas historiográficas que destaco en esta presentación incorporan señalamientos medulares extraídos de distintos escritos shapinianos: un esbozo de historia de la historiografía de la ciencia internista/externista (1992), el análisis de lo que dio en llamar tradición "neocontextualista" de la historia de la ciencia (1980), su interpretación crítica de la tesis de Merton (1988), la deconstrucción de los límites de la práctica científica experimental del siglo XVII inglés (1985) y la configuración del vocero de la verdad (1994). Reconstruiré la historia shapiniana de la historiografía internista/externista y propondré una 
historia de la historiografía de la ciencia inglesa del siglo XVII que señala a Merton en un extremo y las producciones historiográficas de Shapin en el otro. Ambas historias tienen como objetivo mostrar la manera en que Shapin transita a través de un conjunto de tópicos comunes a ciertas realizaciones historiográficas de la ciencia a la vez que efectúa una apropiación no prevista de distintos elementos conceptuales a la mano. En esos desplazamientos se imbrican lo que podemos llamar una "causalidad figural positiva" y una "causalidad figural negativa" por medio de las cuales se señalan textos previos como anuncios de otros posteriores en la promesa siempre renovada de consumar una figura, así como también textos previos que anuncian una promesa incumplida cuyo cumplimiento es una empresa no sólo imposible sino estéril.

La historia de la historiografía de la ciencia internista/externista que Shapin crea es un prototipo legitimador de su propio proyecto: la consumación de la representación de la contingencia y la naturaleza de final abierto del conocimiento científico.

En la historia de la historiografía de la ciencia inglesa del siglo XVII pretendo señalar un conjunto de tópicos - la Revolución científica, los orígenes de la ciencia moderna en Inglaterra, la legitimación de la filosofía experimental, la relación de la filosofía experimental y el puritanismo - en los que Merton se vio involucrado por sus adversarios o sus intérpretes y a través de los cuales Shapin transita cambiando radicalmente el sentido de lo propuesto.

\section{Una historia de la historiografía de la ciencia internista/externista}

La institucionalización del discurso interno/externo en el campo de la historia y la sociología de la ciencia se consolidó en la segunda mitad del siglo $\mathrm{XX}$ en torno a los problemas de la naturaleza de la ciencia y de la determinación de las causas del cambio científico. Shapin considera que el problema sustantivo que intentaron resolver las producciones historiográficas internista y externista es el de la delimitación de la práctica científica. Que un elemento causal del cambio científico sea considerado propio-interno o ajeno-externo a la ciencia del pasado es el resultado del modo en que se configuran los límites de la ciencia en un relato histórico.

En ese sentido, la historia shapiniana del debate historiográfico, al mismo tiempo que bosqueja el camino hacia una conciencia de la contingencia del trazado de los límites de la práctica científica, señala el carácter contingente de las representaciones históricas de los límites de la ciencia e incluso de la representación de la historia de la historiografía en tanto construcciones retrospectivas del canon.

Si bien Shapin (1992) propone llevar adelante "una arqueología muy breve y esquemática" del discurso interno/externo, su propuesta puede elevarse al rango de genealogía en la medida en que la historia que configura construye un canon de la historia y la sociología de la ciencia internista/externista.

El relato shapiniano comienza señalando la relevancia y la centralidad de la sociología de la ciencia como acto inaugural del debate internista/extenista. No obstante la familiaridad del discurso interno/externo en el campo de la filosofía 
de la ciencia, Shapin traza límites: "no creo que la filosofía haya sido nunca un jugador importante en la contienda interno/externo" (SHAPIN 2005, p. 72). Es Robert Merton quien abre la trama: "Un linaje más pertinente para los usos actuales se remonta a los orígenes de la sociología de la ciencia desarrollada en el ámbito académico y, especialmente, al escenario del cual surgió la primera obra de Robert Merton en los años treinta" (SHAPIN 2005, p. 73). En Ciencia, tecnología y sociedad en la Inglaterra del siglo XVII (1938) se invoca por primera vez lo interno y lo externo como "aproximaciones a las teorías (si bien es cierto que informales) del cambio social y cultural en la ciencia" (SHAPIN 2005, p. 74).

Es el acto mismo de ese señalamiento como inicio de la trama lo que le da presencia a Merton como promesa a seguir. Esa visibilización se refuerza al exhibir la extrañeza que ese discurso provocó en el contexto académico de los años treinta. A pesar de que la relación entre el protestantismo y la ciencia estaba siendo estudiada en esos años por historiadores como Dorothy Stimson y R. F. Jones, Shapin destaca el desconcierto que provocó el vocabulario interno/externo.

Mediante esa presentación, el autor eleva, en primera instancia, las categorías mertonianas de lo interno/externo como figura de la delimitación de la práctica científica en general y de la práctica disciplinar de la sociología de la ciencia. La figura mertoniana de la delimitación científica separa la dimensión social de la ciencia del elemento conceptual: por un lado, la ciencia como producto racional autónomo y, por otro lado, en tanto institución social, como el resultado no previsto de acciones sociales no racionales. Consecuentemente, prefigura el cambio científico distanciando la dinámica de legitimación y expansión de la práctica científica de los cambios conceptuales al excluir la pertinencia de los factores políticos, económicos, sociales o religiosos para la explicación del cambio conceptual. $Y$ en ese mismo movimiento, el vocabulario interno/externo opera una delimitación disciplinar instalando la explicación sociológica externa en un papel complementario en relación con la historia de la ciencia interna.

La apropiación por parte de los historiadores y sociólogos de la ciencia del vocabulario interno/externo consumó la figura de la delimitación en términos de una dicotomía omnipresente capaz de dar respuesta a la mayoría de los problemas historiográficos de la ciencia, a la vez que fundó un abismo ontológico entre la ciencia y lo social. Se exhibió cada uno de los lados de la dicotomía como una clase natural cuyos miembros compartirían las características esenciales con características esenciales cuyos miembros compartirían. Se impulsó, además, una relectura desde esas categorías de los trabajos historiográficos que no habían sido escritos en esos términos. Así, se calificó de externista, sin que hubiera lugar a dudas, el artículo de Boris Hessen, "The Social and Economic Roots of the Newton' Principia" (1931), a pesar de que, de acuerdo con las categorías marxistas, careciera de sentido considerar la base económica y la superestructura como factores que influirían desde el exterior en la producción del conocimiento científico. Más aún, tanto Boris Hessen como la perspectiva marxista de los historiadores británicos de la ciencia fueron elevados a la categoría de externistas extremos. 
Si bien Merton no parece ajeno a ese proceso por el cual lo interno y lo externo fueron modelados como categorías metafísicas, Shapin ve en la representación mertoniana de la ciencia en tanto institución social un anuncio del carácter contingente de la constitución y legitimación de la práctica científica. La determinación de la figura de la acción no racional de Wilfredo Pareto como vínculo precedente que la tesis de Merton consuma permite avanzar el relato de Shapin más allá de las dicotomías cristalizadas a partir del par interno-externo, incluso más allá de la dicotomía racional-no racional que la referencia paretiana introduce. Subyace a la explicación de Merton de las conexión entre las formas de puritanismo inglés y la legitimación de la ciencia en el siglo XVII una teoría de la acción de influencia paretiana. Entre las prácticas racionales, completamente comprensibles, y las prácticas irracionales incomprensibles, Merton acepta la categoría paretiana de conducta no racional, que puede ser comprendida desde el punto de vista sociológico. Dado que los sentimientos (no racionales e inconscientes) y el lenguaje religioso en el que se expresaban eran los recursos culturales predominantes en el siglo XVII inglés, toda forma nueva de acción social debía buscar legitimidad exhibiendo públicamente su compatibilidad con aquellos sentimientos y con sus expresiones (SHAPIN 1988, p. 595; 598-601). Así, afirma Merton:

[n]o presentamos el movimiento históricamente concreto del puritanismo como un requisito para el sustancial impulso de la ciencia inglesa por aquel entonces; otros movimientos ideológicos funcionalmente equivalentes podrían haber servido para suministrar a la ciencia en ascenso derechos ampliamente reconocidos a la legitimidad. [...] Ocurrió que el puritanismo brindó un importante apoyo (pero no exclusivo) en aquel tiempo y lugar históricos. Pero esto no lo hace indispensable [...] [aunque] tampoco convierte al puritanismo en algo epifenoménico y sin importancia (MERTON 1984, p. 20).

El elemento no racional sobre el cual modela el proceso de legitimación de la ciencia inglesa lleva a Merton al reconocimiento de la contingencia de los recursos culturales a la mano y de la inestabilidad de la legitimación misma. De allí, la necesidad de codificar el ethos científico para recordar a la sociedad y a los científicos qué debía ser defendido si se pretendía continuar con el desarrollo de la ciencia.

La reconstrucción genealógica de la historia internista/externista le permite a Shapin no solo señalar el carácter contingente de la delimitación científica sino también de las historias de la historiografías de la ciencia. En esa tarea señala al historiador internista de la ciencia A. Rapert Hall para exhibir una historia de la historiografía internista/externista contrapuesta a la propia. La historia que Hall escribe es la consumación de la promesa singular de la figura de la ciencia esencialmente teórica sin contaminación.

Hall destaca que la construcción historiográfica de Merton apela a la historia de la sociedad pasada para extraer los principios explicativos del cambio científico revolucionario del siglo XVII en vez de abrevar en la historia conceptual de la ciencia. 
El señalamiento de Hall de los vínculos historiográficos del trabajo de Merton indica el enlace con una corriente historiográfica que operó en el siglo XIX y fue retomada en los años treinta del siglo XX, la cual deriva su fuerza de "dos majestuosas concepciones victorianas: la observación de Marx de que el carácter de la sociedad está determinado por su economía, junto con el descubrimiento compatible aunque distinto de los antropólogos de que la 'cultura' es una unidad" (HALL 1968, p. 90). La conjunción de esas tesis da por resultado que:

[...] los pensamientos de los hombres sobre cualquier tópico [...] no son independientes de sus pensamientos sobre otros tópicos ni del estado económico de la sociedad en el que viven. Así, si concedemos que "no independiente de" es equivalente a "causalmente determinado por", tenemos una noción historiográfica que está hoy fuertemente abierta a la discusión" (HALL 1968, p. 90).

La monografía de Merton es para Hall la consumación de esa conjunción, aunque a través de un vínculo intermedio en el esquema prefiguración-figura-cumplimiento constituido por la obra de Boris Hessen sobre los Principia de Newton. Desde esa perspectiva, Hall le atribuye a Merton un nexo con un pasado historiográfico que no dirige la atención hacia lo nuevo y original de la sociología de la ciencia, sino que la emplaza como la finalización de una tradición decadente.

Treinta años después de la revisión de Hall, Shapin escribe su versión de la historia cuando se había pasado del triunfo de la historia internista de la ciencia a la disolución del poder de las categorías de lo interno/externo como herramientas de análisis. La genealogía negativa que realiza Hall en su reconstrucción historiográfica de la disputa internismo/externismo, lejos de fijar de modo concluyente el triunfo de la historia interna de la ciencia, acentúa el carácter contingente de toda apropiación retrospectiva. La representación de la historia de la historiografía internista/externista de Hall está también abierta a expropiaciones y, como tal, Shapin la señala como una promesa estéril toda vez que construye sus genealogías sobre las consumaciones de una representación esencialista de la ciencia.

De acuerdo con nuestro recorrido, la reconstrucción de Shapin efectúa apropiaciones de la monografía de Merton en dos sentidos: en primer lugar, como la representación modelada por el vocabulario interno/externo de los límites de la práctica científica, incluso los límites disciplinares de la historia internista y la sociología externista de la ciencia. Esa figura transciende en la conciencia de la relevancia del problema de la delimitación de la práctica científica y del carácter contingente de esa delimitación, aunque en el cumplimiento de la promesa de marcar los límites científicos, Shapin deba unir lo que Merton desunió: el orden social y el orden del conocimiento.

En segundo lugar, la tesis de Merton es señalada como figura del cambio social y cultural de la ciencia: para que la actividad científica se institucionalizara y se aceptara en su propio derecho, los científicos se vieron obligados a legitimar 
su práctica en términos de los recursos culturales disponibles. Shapin eleva la interpelación a los recursos culturales a un programa de investigación y esa expropiación indica el camino de la indagación de la "infraestructura cultural" de la ciencia, que su propia obra consuma.

\section{Una historia de la historiografía de la ciencia inglesa del siglo XVII}

En "Social Uses of Science" (1980), Shapin presenta un cuerpo de escritos historiográficos que pretende romper con el vocabulario interno/externo y con los compromisos asumidos en la historiografía respectiva. Exhibe dichas obras como formando parte de un enfoque "neocontextualista". Esta categoría de ninguna manera refiere a un cuerpo de trabajos homogéneos. Más bien constituye una construcción de Shapin que enfatiza una serie de convergencias entre un conjunto de producciones provenientes de la antropología y de la historia de la ciencia a las que llama "implícitamente antropológicas" e "implícitamente marxistas".

El acto shapiniano de creación de esa tradición neocontextualista señala la figura del carácter social del conocimiento científico modelada en los trabajos de Mary Douglas. Su tesis principal acerca del conocimiento como constitutivamente social permitiría avanzar en una epistemología social que proporcione a los historiadores de la ciencia "lo que los marxistas han tenido siempre - un programa para interpretar la actividad intelectual en un contexto social" (SHAPIN; BARNES 1977, p. 63).

A partir de los trabajos de Douglas, sostiene Shapin, se pueden concebir

146 las afirmaciones científicas como estrategias modeladas por grupos sociales para construir y sostener un orden social. Los actores sociales participantes los grupos de científicos contrapuestos - harán valer sus recursos culturales en pos de producir actos de habla en los que se establece una estructura clasificatoria o su reconfiguración, se erige una ontología y se procura la legitimación, el quebrantamiento, la defensa o la deslegitimación de un orden social. Desde la mirada de Shapin, los trabajos "implícitamente marxistas" como los de Margaret y James Jacob y los de Christopher Hill Ilevan las marcas de la consumación de las tesis de Douglas. Ellos jugaron un papel de importancia a la hora de construir un enlace entre epistemología, ontología, historia de la ciencia e historia política. La historia de la ciencia de Shapin también lleva las marcas de esa consumación:

Nos movemos más allá de preguntar qué creen los científicos para preguntar qué están tratando de hacer; significa que entendemos las creencias en términos del repertorio de conocimiento heredado y transmitido socialmente que está a disposición de los científicos para sus propósitos; implica comprender el significado de las proposiciones científicas haciendo referencia a su contexto de uso; y nos permite tratar de explicar las creencias científicas, sean "verdaderas" o "falsas", utilizando toda la gama de recursos disponibles para el historiador (SHAPIN 1985, p. 50).

Lejos parecen estar los trabajos de Merton. Sin embargo, considero que parte de los historiadores sumidos en este neocontextualismo pueden ser reunidos en una trama diacrónica en la que cada texto se apropia de la tesis 
de Merton como la figura de la relación estrecha e indubitable entre ciencia y religión en "los orígenes de la ciencia moderna" que deberá ser consumada por medio de nuevas representaciones que asuman plenamente la imbricación entre orden social y orden del conocimiento.

Parte significativa de la historiografía de la ciencia de la década de los años 1960 centra su producción en el empeño por clarificar el cambio científico. Pero ahora el cambio científico se restringe al concepto de Revolución científica, tal como fue acuñado por Koyré y Butterfield para dar unidad a una gama de fenómenos constituidos en el origen de la ciencia moderna. La cristalización de la discusión en torno a la Revolución científica involucró una nueva apropiación de la tesis de Merton. Ella es retrospectivamente señalada como la respuesta procedente de la historia sociológica de la ciencia a la pregunta por las causas que dieron origen a la ciencia moderna. Sin embargo, en ninguna parte de Science, Technology and Society in Seventeenth-Century England, Merton afirma que va a explicar el origen de la ciencia moderna y ello está plenamente justificado porque, en el momento en que fue escrita la monografía, el concepto de Revolución científica no había sido acuñado en el sentido en que se va a difundir posteriormente en la historiografía de la ciencia.

De los historiadores que siguieron a Alexandre Koyré, A. Rupert Hall parece ser el responsable de señalar la obra de Merton como un intento de explicación de la Revolución científica. En "Merton Revisited, or Science and Society in the Seventeenth Century" (HALL 1963), sostiene que el trabajo de Merton, una de "las formas más crudas" de la interpretación socioeconómica de la Revolución científica, "ha muerto sin comentarios".

No obstante, lejos de darse por muerta, entre 1964 y 1965 es vista como parte de la polémica suscitada alrededor de la obra de Christopher Hill Intellectual Origins of English Revolution, publicada en las páginas de Past and Present. Todos los contendientes tenían en claro que lo que se estaba tratando de explicar eran las causas de la Revolución científica. Al ser considerada la Revolución científica un cambio fundamentalmente conceptual, algunos historiadores se embarcaron en demostrar críticamente que la tesis mertoniana no podía dar cuenta del mismo. Otros, en cambio, se apropiaron de dicha tesis para mostrar que la cuestión perenne de la relación entre religión y ciencia en los orígenes de la ciencia moderna solo podía resolverse asumiendo su dimensión política.

H. F. Kearny (1964) comienza la sucesión de críticas y contraargumentos. No duda en ubicar el trabajo de Hill formando parte de una línea interpretativa sociológica de la Revolución científica que reúne a Merton y a Zilsel con la generación de historiadores de la ciencia británicos que desarrollaron una visión marxista en los años cincuenta. La innovación de Hill radicaría en dar una respuesta desde el campo de la historia general inglesa más que desde el ámbito de los estudios especializados de historia de la ciencia. En la visión de Kearny, Hill busca "las causas" del surgimiento de la ciencia moderna en el estado de la sociedad inglesa correspondiente a la década de los años $1640 \mathrm{sin}$ lograr alcanzar su objetivo. 
Theodore Rabb entra en la contienda afirmando en relación con el trabajo de Hill que, si el tópico en discusión es el "origen" de la ciencia moderna, la cuestión es mostrar qué papel jugó la religión para estimular los grandes avances en anatomía, física y astronomía, "Ios cuales son conocidos como la Revolución científica". En 1962, Rabb ya había criticado el trabajo de Merton, señalando que no había podido demostrar el origen puritano de la ciencia. Aunque el puritanismo no puede ser considerado el factor principal o su causa, afirma, indudablemente ayudó a expandir más rápidamente el interés creciente en la ciencia (RABB 1990, p. 214-215). Sin embargo, con ese argumento, Rabb suscribe la tesis mertoniana al demostrar que Merton no pudo realizar lo que en realidad nunca se había propuesto hacer.

En respuesta a sus críticos, Hill destaca que, si bien la Revolución científica fue un movimiento europeo, su análisis en términos nacionales podría contribuir a la comprensión de la relación de la ciencia con la sociedad. No cabe duda de que la relación entre el protestantismo y el origen de la ciencia moderna haya quedado suficientemente fundamentada en la historiografía de la ciencia previa. Sin embargo, su historia muestra que el cambio científico no es el producto del protestantismo o del puritanismo, sino que ciencia y puritanismo surgieron del cambio por el cual "los valores urbanos e industriales reemplazaron a los valores propios de una sociedad principalmente agraria" (HILL 1964, p. 89). A principios de la década de los años 1640,

[I]os burgueses londinenses y la "clase media" que formaba la columna vertebral de los ejércitos parlamentarios habían discutido durante casi un siglo las nuevas ideas científicas y habían reivindicado el derecho de elegir a los pastores. Habían aprendido a rechazar la autoridad de Aristóteles y la de los obispos, a basarse en la experimentación tanto en el terreno religioso como en el científico, a confiar en la prueba de su propio sentido crítico independiente (HILL 1980, p. 142-143).

De ese modo, el vínculo entre ciencia y puritanismo que en la figura mertoniana mostraba la interdependencia de dos esferas institucionales en una sociedad, en la consumación de Hill se sume bajo la lógica de la guerra revolucionaria.

Barbara Shapiro (1968) vuelve a convocar desde las páginas de Past and Present "una escuela de sociólogos orientados históricamente y de historiadores de orientación marxista, que comienza con Max Weber y culmina con Robert Merton y Christopher Hill" que ha sostenido una íntima relación entre el puritanismo y "la innovación científica" en la Inglaterra del siglo XVII (SHAPIRO 1968 , p. $16-17 ; 1983$, p. 74). La genealogía de Shapiro comienza con la figura modelada ahora por Merton-Stimson-Hill, que sienta como clave de la relación indisoluble entre ciencia y religión la "lógica del protestantismo - la disidencia del disidente- siempre presente en los países protestantes" (HILL 1964, p. 89). La consumación de Shapiro de la figura de la perennidad de la relación ciencia-religión resalta la moderación qua moderación más que el puritanismo de los puritanos moderados, como lo sostenía Hill. En la visión de Shapiro, la distinción entre puritanos y anglicanos asumida en la tesis Merton-Stimson-Hill 
oscureció el hecho de que había existido una amplia categoría intermedia a la que habían pertenecido hombres de la iglesia, políticos y académicos que querían la reforma de la iglesia aunque buscaban medios moderados para llevarla a cabo: los latitudinarios. Los religiosos moderados o latitudinarios estarían más íntimamente conectados con el movimiento científico inglés que los puritanos.

Sin embargo, el cumplimiento que consuma Shapiro porta una transformación de mayor importancia aún, pues avanza sobre terreno epistémico. El punto del vínculo entre ciencia y religión no radica en una ética social y religiosa única, sino en el interés común por el método para alcanzar el conocimiento. Algunos científicos llegaron a considerar que era la investigación científica misma la que proveía la solución para el disenso religioso:

[...] si los métodos de la ciencia fueran inculcados en la mente del público, podrían contribuir a mejorar el clima religioso. Los virtuosi esperaban que eventualmente la ciencia y una religión natural latitudinaria y moderada pudieran servir como los pilares para sostener una vida intelectual en la que la búsqueda tranquila, amistosa y práctica de la verdad y el bien pudieran remplazar el debate abstracto y la guerra civil motivada ideológicamente (SHAPIRO 1968, p. 41).

El método científico enlaza ahora ciencia, religión y orden social.

En torno a la interpretación de la Restauración latitudinaria de Bárbara Shapiro, Margaret y James Jacob provocan un nuevo debate en la década de los años 1970. Realizan la consumación de la representación de las relaciones entre la ciencia y la religión avanzando en el solapamiento de lo político y epistémico.

James Jacob (1975), en diálogo con Shapiro, advierte que los historiadores (incluida Shapiro) asumieron acríticamente las declaraciones de los primeros cronistas de la Royal Society enfatizando la manera en que los miembros de esa institución lograron separar sus obras de la controversia política y religiosa en los años 1640-1650. Así, Shapiro presenta las posturas religiosa y política de la Royal Society emergiendo del deseo generalizado de moderación religiosa, comprensión eclesiástica y orden civil.

Jacob ve cómo las prácticas de cortesía, paciencia y respeto mutuo, que la Royal Society presentaba como dispositivos de protección contra la contaminación política y religiosa, cumplían una misión específicamente política y religiosa. El método científico, que para Shapiro proveía la solución a las disputas religiosas, es para Jacob un instrumento de lucha, aplicado a la política y a la religión con un claro sentido ideológico: limitar la tolerancia religiosa. Operaba excluyendo a dogmáticos y escépticos, lo que conducía a un moderado disenso en el que solo los disidentes inicuos ganaban voz pública. La mesura se configura para Jacob en un mecanismo para establecer una línea de demarcación entre quienes pueden participar y quienes quedan excluidos de la investigación científica y del ámbito social.

Así, la expropiación por parte del "nuevo contextualismo" de la figura mertoniana de la relación entre ciencia y religión consumó la práctica científica como una construcción epistémico-política. 
Ahora bien, en sus trabajos sobre la ciencia inglesa del siglo XVII, Shapin separa por medio de las expropiaciones que consuman las distintas figuras delineadas en las sucesivas controversias dos líneas definidas y complementarias: por un lado, la figura de la delimitación contingente de la práctica científica que parte de la disputa internismo/externismo y se incrusta en la disputa historiográfica acerca del método experimental como dispositivo social y, por otro lado, la figura de la legitimación cultural de la práctica científica que fue consumada como la representación del origen puritano de la ciencia moderna en tanto apropiación de la tesis mertoniana, realizada en los años sesenta.

$\mathrm{Si}$, como lo considera Shapiro, los latitudinarios creían la ciencia misma el locus en el que se creaba la mesura necesaria para remediar el conflicto religioso, entonces esa autora deja abierto un espacio historiográfico para interrogar por qué las reglas metodológicas experimentales podían instituir un orden social. Y si, como James Jacob responde, la organización de la práctica científica constituyó un dispositivo ideológico para luchar por un determinado orden político-religioso, cabe preguntar sobre el despliegue de ese proceso de construcción social. Ambos interrogantes señalan el problema de los límites de la práctica científica que Shapin y Schaffer (1984) asumen plenamente en el intento de diluir la exterioridad de lo social en relación con la ciencia.

Si aceptamos la pregunta: "¿Qué hace el filósofo natural por el mero hecho de expresar las reglas del método?" como central en El Leviathan y la bomba de vacío, vemos en la respuesta de los autores el despliegue de la significación de ese "hacer". Según lo expresan Shapin y Schaffer:

[...] intentamos exhibir el método científico como forma cristalizada de organización social y como un medio de regular la interacción social dentro de la comunidad científica [...]; trataremos las controversias sobre el método científico como disputas sobre distintos patrones de hacer las cosas y de organizar a los hombres para fines prácticos (SHAPIN; SCHAFFER 2005, p. 44).

El acto performativo de dictar y sostener las reglas del método experimental conlleva la creación de un espacio intelectual constituido por las prácticas discursivas-sociales y un espacio físico donde se disciplinan esas prácticas por medio del control que ejercen los miembros competentes. Al mismo tiempo se construyen los límites para conformar un colectivo social organizado políticamente por quienes pretenden legitimar una forma de vida filosófica propuesta. Esta organización institucional se postula como posible organización política de la sociedad. Así, El Leviathan y la bomba de vacío avanza sobre el objeto privilegiado de la concepción epistemológica clásica, el método científico, y une lo que Merton desunió a través de su vocabulario interno-externo: el orden social y el orden del conocimiento.

Ahora bien, dar cuenta del método como un elemento central en la delimitación de la práctica científica del siglo XVII inglés no resuelve al mismo tiempo el problema de su legitimidad: 
Incluso en la Royal Society, [...] el programa experimental estaba lejos de estar sólidamente institucionalizado [...] para que la filosofía experimental se estableciera como una práctica legítima varias cosas debían hacerse. Primero, requería reclutas [...]. Segundo, el papel del filósofo experimental y las prácticas lingüísticas apropiadas a una comunidad experimental debían ser definidas y debían ser públicas (SHAPIN; SCHAFFER 2005, p. 113-114).

Shapin realiza un desplazamiento historiográfico desde la figura de la legitimación de la ciencia inglesa del siglo XVII por medio de los valores protestantes hasta poner en cuestión no solo los valores religiosos como punto central del proceso, sino también la legitimación misma de la filosofía experimental en la cultura de la Restauración.

En A Social History of Truth, afirma que va a presentar una historia que podría ser definida como una de las "historias de los orígenes", la historia acerca de los orígenes gentlemanly de la filosofía natural experimental y observacional inglesa en el siglo XVII (SHAPIN 1994, p. XVIII). Sin embargo, la referencia a las "historias de los orígenes" es un acto de apropiación de los avatares historiográficos señalados anteriormente. Al igual que Merton, Shapin no se interesa por dar respuesta al origen sino a la legitimación de la ciencia del siglo XVII inglés. En "'A Scholar and a Gentleman': The Problematic Identity of the Scientific Practitioner in Early Modern England", postula su pretensión de contribuir y extender un cuerpo de teorías sociológicas que se ocuparon de las relaciones entre la cultura y el cambio institucional. Justamente, resalta la relación entre Weber, Merton y Skinner en el intento de explicar los procesos de institucionalización de una práctica social innovadora. La continuidad que Shapin ve entre su obra y ese cuerpo teórico se halla en la tesis según la cual las prácticas sociales logran su institucionalización uniendo su actividad con los principales reservorios de legitimación asentados en la cultura local. Ese señalamiento resalta su propio interés por el carácter contingente de los valores culturales que fueron activamente seleccionados para dar legitimidad a la ciencia.

Si bien acepta que la religión puritana proporcionó recursos de legitimación para dar sustento a la nueva forma de vida de la filosofía experimental, se propone, no obstante, mostrar que la cultura tradicional del gentleman habría sido la fuente de legitimación más importante de la nueva práctica científica. La práctica cultural conocida como "la filosofía experimental inglesa" constituyó una nueva cultura que emergió en parte mediante una útil reubicación de las convenciones, códigos y valores de conversación gentlemanly en el dominio de la filosofía natural (SHAPIN 1994, p. XVII). Pero la historia de la legitimación que Merton consideró finalizada con un rápido triunfo recién comenzaba: la institucionalización de la filosofía experimental en Inglaterra aún no había sido lograda en el siglo XVII.

Si resumimos los señalamientos genealógicos diseñados desde la misma obra shapiniana, podemos considerar el artículo "Understanding the Merton Thesis" (1988) como un nuevo y central punto de partida de la apropiación que realiza de Merton. En ese artículo, muestra cómo la tesis de Merton ha sido mal interpretada tanto por los seguidores como por sus críticos y a partir 
de esa demostración comienza a desarmar los límites establecidos dentro del terreno de la sociología del conocimiento científico. Así, en los años noventa, enfrenta el lugar común del repudio contra Merton. Se asume como consumación del programa Weber-Merton-Skinner en el interés por los valores culturales en la comprensión del cambio científico. Sin embargo, construye esa síntesis genealógica en pos de mostrar que en la legitimación de la ciencia inglesa del siglo XVII no operaron fundamentalmente los valores puritanos sino los de la cultura gentlemanly.

Desempolva la disputa internismo/externismo y la instituye en una obra mertoniana. Sin embargo, su objetivo apunta a mostrar la manera en que el Programa Fuerte llevó adelante el proceso más fructífero de "desinflar" la dicotomía entre factores internos y factores externos. Mientras Merton, como figura canónica de la disputa, coadyuvó a erigir lo interno/externo en un dualismo metafísico, el Programa Fuerte, por medio de un proceso de debilitar la dicotomía, condujo a romper con los compromisos epistemológicos y metafísicos gestados a la luz de la disputa, que habían quedado, parafraseando a Koyré, en la inconsciencia de las cosas en las que ya no se piensa.

La construcción shapiniana de la línea interpretativa "neocontextualista" que asumió el solapamiento de la historia política con la historia de la ciencia parecía llevarnos lejos de la tesis de Merton. Shapin la enlaza con la línea neodurkhemiana de Mary Douglas y con un compromiso implícito con un enfoque marxista. No obstante, tal como lo he mostrado, los distintos textos señalados

152 por Shapin (1980) e incluso parte de su obra realizan sucesivas consumaciones de la representación de la relación de la ciencia y la religión en el siglo XVII inglés provocando mutaciones que acentuaron el carácter contingente de los límites de la práctica científica y de los valores culturales, recursos indispensables en la construcción de esos límites convencionales como en la cristalización de esa práctica en un contexto social determinado.

\section{Referencias bibliográficas}

AUERBACH, Erich. Mimesis. La representación de la realidad en la literatura occidental. Mexico: FCE, 1996 [1942].

Figura. Madrid: Trotta, 1998 [1944].

AUSTIN, John L. Cómo hacer cosas con palabras. Palabras y Acciones. Buenos Aires: Paidós, 2008 [1962].

DOUGLAS, Mary. Símbolos Naturales. Madrid: Alianza, 1988 [1970].

Implicit Meaning: Essays in anthropology. Londres: Routledge \& Kegan Paul, 1975.

HALL, A. Rupert. Merton Revisited, or Science and Society in the Seventeenth Century. In: BASALLA, George (ed.). The Rise of Modern Science: Internal and External Factors? Lexington, Mass.: D. C. Heath, 1968, p. 89-96 [1963]. 
HILL, Christopher. Puritanism, Capitalism and the Scientific Revolution. Past and Present, no 29, Oxford: Oxford University Press, 1964, p. 88-97.

Los orígenes intelectuales de la Revolución Inglesa. Barcelona: Crítica, 1980 [1965].

JACOB, James. Restoration, Reformation and the Origins of the Royal Society. History of Science, no 13, Cambridge: Science History Publications, 1975, p. 155-176.

Robert Boyle and the English Revolution. A Study in Social and Intellectual Change. New York: Burt Franklin, 1977.

JACOB, Margaret. The Newtonians and the English Revolution 1689-1720. New York: Gordon and Breach Science Publishers, 1990 [1976].

Newtonianism and the Origins of the Enlightenment: A Reassessment. Eighteenth-Century Studies, no 11, Baltimore: The Johns Hopkins University Press, 1977, p. 1-25.

; JACOB, James. Seventeenth century science and religion: the state of the argument. History of Science, $n^{\circ} 14$, Cambridge: Science History Publications, 1976, p. 196-207.

The Anglican Origins of the Modern Science: The Methaphysical Foundations of the Whig Constitution. Isis, no 71: 2, Chicago: The University of Chicago Press, 1980, p. 251-267.

MERTON, Robert. Ciencia, tecnología, sociedad en la Inglaterra del siglo XVII. Madrid: Alianza, 1984 [1938/1970].

SHAPIN, Steven. Social Uses of Science. In: ROUSSEAU, George S.; PORTER, Roy (eds). The Ferment of Knowledge: Studies in the Historiography of Eighteenth-Century Science. Cambridge: Cambridge University, 1980, p. 93-139.

. What is the History of Science? History Today, n 35, Londres, 1985, p. 50-51.

. Understanding the Merton Thesis. Isis, $n^{\circ} 79$, Chicago: The University of Chicago Press, 1988, p. 594-605.

. 'A Scholar and a Gentleman': The Problematic Identity of the Scientific Practitioner in Early Modern England. History of Science, no 29, Cambridge: Science History Publications, 1994, p. 279-327.

- Disciplina y delimitación: la historia y la sociología de la ciencia a la luz del debate externismo-internismo. In: MARTÍNEZ, Sergio; GUILLAUMIN, Godfrey (comp.). Historia, Filosofía y Enseñanza de la Ciencia. México: Universidad Nacional Autónoma de México, 2005, p. 67-119 [1992].

A Social History of Truth. Chicago: Chicago University Press, 1994. 
SHAPIN, Steven; BARNES, Barry. Where is the Edge of Objectivity? [Douglas, Implicit Meanings]. The British Journal for the History of Science, $\mathrm{n}^{\circ}$ 10, Cambridge: Science History Publications, 1977, p. 61-66. ; SCHAFFER, Simon. El Leviathan y la bomba de vacío: Hobbes, Boyle y la vida experimental. Bernal: Universidad Nacional de Quilmes, 2005 [1985].

SHAPIRO, Barbara. Latitudinarism and Science in Seventeenth-Century England. Past and Present, no 40, Oxford: Oxford University Press, 1968, p. 16-41. . Probability and Certainty in Seventeenth-Century England: a Study of the Relationships between Natural Science, Religion, History, Law and Literature. Princeton: Princeton University Press, 1983.

WHITE, Hayden. Figural Realism. Studies in the Mimesis Effect. Baltimore: The Johns Hopkins University Press, 1999.

Ficción histórica, historia ficcional y realidad histórica. Buenos Aires: Prometeo, 2010.

$$
154
$$

